\title{
Cyclic behavior of precast concrete beam-column connection using steel fiber reinforced cast-in-place concrete
}

\author{
Vera Agustriana Noorhidana ${ }^{1, *}$, John P. Forth ${ }^{2}$ \\ ${ }^{1}$ Department of Civil Engineering, Universitas Lampung, Indonesia \\ ${ }^{2}$ School of Civil Engineering, University of Leeds, The United Kingdom
}

\begin{abstract}
Three equivalent exterior precast concrete beam-column (PCBC) connections have been investigated in this study in orderto analyze the effect of steel fiber reinforced concrete (SFRC) as cast-in-place (CIP) on the seismic performance of the PCBC connection. The connection was designed as a ductile connection for a moment-resisting frame and consists of a precast Ubeam, precast column with corbel, interlocking bars, and CIP-concrete to connect the precast beam to precast column. The volume fractions of steel fiber incorporated within the CIP-concrete were $0 \%, 0.5 \%$ and $1 \%$. A quasi-static load was applied vertically to the beam tip of the PCBC specimen. The results showed that the steel fibers contained within the CIP-concrete provided $2 \%$ increase of the maximum load, $17.7 \%$ increase of the energy dissipation, and increase in the joint stiffness of the PCBC connection. The steel fibers delayed the onset of cracking and slowed down the crack propagation, resulting in shorter cracks in the joint core of PCBC specimen, which correlates well with the deflection-hardening characteristic found from the modulus of rupture test.
\end{abstract}

Keywords: precast concrete, beam-column, connection, steel fiber, cast-in-place, energy dissipation

\section{Introduction}

Fiber reinforced concrete (FRC) is a cement based material reinforced with short randomly distributed fibers. FRC is an alternative to improve the structural performance under seismic loading. Currently, fibers are produced from several materials such as steel, glass, carbon, and steel combined with synthetic fibers (nylon, acrylic, polyester, etc.). Research has shown that FRC has better mechanical properties when compared to plain concrete $[1,2]$. The fibers, which are dispersed homogeneously in the concrete, can bridge cracks and distribute tensile stresses so that crack sizes become smaller and are spread evenly [3]. The fibers can also control crack formation, delay crack propagation, and improve ductility of the concrete. In addition, the presence of fibers in concrete can enhance the bond between concrete and deformed steel bars $[4,5]$.

The ability of fibers to enhance the mechanical properties depends on several factors, such

\footnotetext{
*E-mail: vera.agustriana@eng.unila.ac.id
}

as fiber type, fiber modulus, fiber aspect ratio, fiber strength, surface bonding characteristics, fiber content, fiber orientation, and aggregate size and strength of the concrete matrix itself. Steel fibers are more widely used because they have a relatively high strength and modulus of elasticity, they are protected from corrosion by the alkaline environment of the cementitious matrix, and the bond strength between concrete and fiber can be enhanced by mechanical anchorage or surface roughness [6]. Hooked-end fibers enhance end anchorages significantly when compared to straight fibers; they increase the energy absorption capacity and concrete toughness [7].

The addition of fiber has been effective in improving the performance of column-beam joints due to gravity and cyclic loads, both in monolithic and precast joints [8-10]. Steel fiber reinforcement in concrete can also reduce the density of the transverse reinforcement in the beam-column joint.

Precast concrete systems continue to develop and have become more popular in the last few decades. These systems are believed to be an alternative solution to many of the problems in the con- 
struction industry, because they offer advantages in terms of quality, time, and cost, in comparison with cast-in-situ construction. Furthermore, the manufacture of precast units in a controlled factory environment improves the quality of the material selection, mixing, molding, and the curing process, such that the quality and strength can be better guaranteed. These advantages make precast systems potentially more appealing to the construction industry.

Many studies have been carried out to improve our understanding of the joint behavior between precast concrete elements. Several studies on precast concrete beam-column (PCBC) joints, with different designs and detailing, which were subjected to cyclic loading, have shown that the precast connections provide sufficient strength and energy dissipation compared to monolithic specimens [10-12].

In general, the types of beam-column connections that have been developed in terms of precast concrete moment-resisting frames are bolted, welded, prestressed, cast-in-place (CIP), or a combination consisting of any two or more of these. Welded connections could satisfy strength and stiffness requirements; however, they can introduce excessive heat, which can damage or cause cracks in the adjacent precast concrete [13]. In addition, the implementation of this type of connection needs skilled site staff who can guarantee the quality of the welding in the connection $[8,14]$.

The easiest method to connect precast elements on site is using bolted connections. Unfortunately, this method requires a high degree of precision in placing the channels or steel plates before casting the precast elements. Problems also exist due to the sliding risk [14]. Another study negated the sliding risk by providing additional tolerances in the bolt holes. However, this caused an initial loss of stiffness in the connection [15].

The CIP-concrete method benefits from the monolithic advantages of reinforced concrete systems as it will help to achieve a more continuous/composite section. This type of hybrid system is recommended for seismic designed buildings [11]. It also allows more tolerance in the precast connections. Unfortunately, it takes longer to install as the concrete has to gain strength and it needs additional formwork and scaffolding on site. All of these factors will lead to an increase in cost and construction time, although this can be off-set to some degree by the improved monolithic structural system.

The main objective of this research is to study the effect of steel fiber reinforced concrete (SFRC) as a material in CIP-connections to the seismic performance of PCBC joints, in terms of the maximum load, the energy dissipation, and the crack pattern. The type of precast beam-column connection discussed in this study has been developed in a previous study. The connection offers several advantages; this connection will negate the need for high precision engineering, hence increasing practicality; reduce the use of formwork due to the use of a precast partial U-beam (acting as permanent formwork); and lower the volume of CIP-concrete. The use of corbels, which support the precast beam, will minimize the need for scaffolding. This new connection also avoids the use of welding, and (potentially) bolts and pre-stressing, which therefore leads to a reduced need for skilled labor and a reduction in the construction time. It may be noted that bolts for any additional corbels required in this connection design are installed on the site before the installation of the precast beam element and are easy to install precisely. So, there should not be a problem regarding precision, sliding risk, and initial loss of stiffness. Overall, this new connection can be expected to offer a more economical and practical solution [16].

\section{Research significance}

This study illustrates that the steel SFRC used as CIP has the potential to increase the seismic performance of a PCBC connection. Steel fibers can slow down the spread of cracks and increase the energy dissipation of the joint.

\section{Experimental program}

A beam-column specimen used in this investigation consisted of one precast concrete beam and one precast concrete column joined using CIP- 


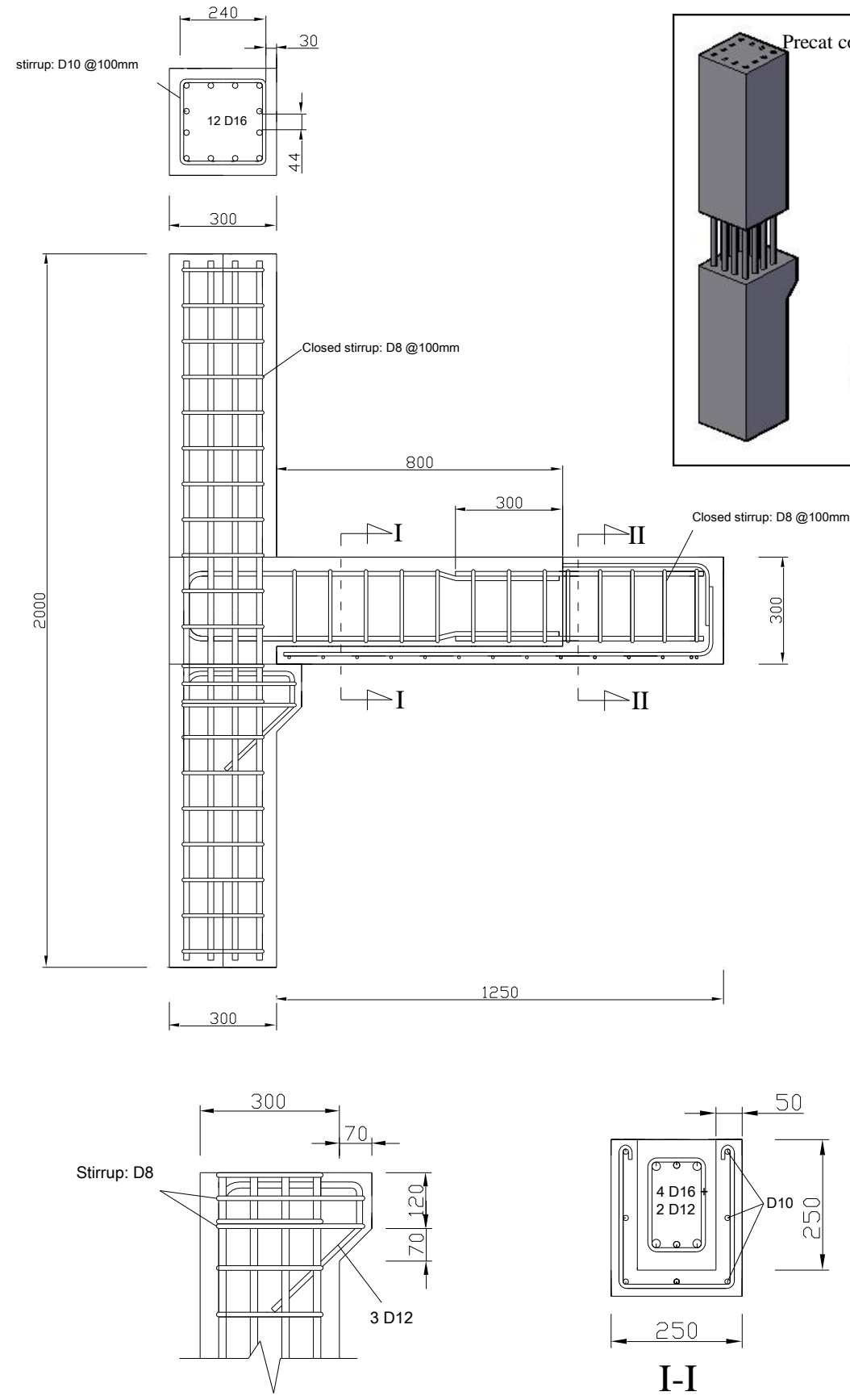

(b)

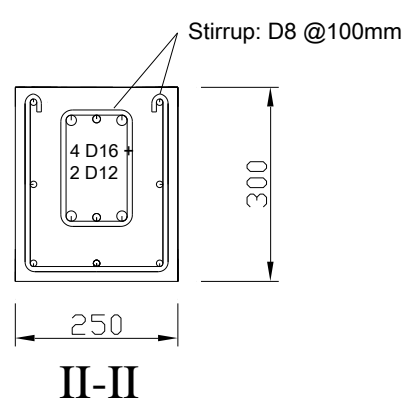

(c)

Fig. 1. Reinforcement detail of PCBC specimen, (A) Isometrics of PCBC connections, (B) Corbel reinforcement, (C) Beam cross sections. PCBC, precast concrete beam-column. 
concrete, and represented a half-scale of an exterior beam-column joint of a moment-resisting frame. The length of the column and the beam were determined based on the location of the contra-flexure points determined via a software analysis of a representative planar frame. The prototype building was rectangular (three bays - three stories high).

Figure 1 shows the reinforcement details of the PCBC specimens, whereas Figure 1B presents the $\mathrm{PCBC}$ specimen as an isometric. The construction process of the joint in the test rig is as follows: (1) Precast columns were vertically set up in the test rig. Column ends were restrained by steel plates, which were bolted to the test rig; (2) One end of the precast U-beam was horizontally placed on the corbel, while the free end was supported by scaffolding (temporary supports, which on site would not be required); (3) All reinforcements (interlocking bars and stirrups) in the joint core and the beam core were installed; (4) The joint core was covered by the form and sealed to avoid the concrete mix leaking from the form; (5) The connection region was cast using CIP-concrete; (6) One day after casting, the joint core was grouted using a non-shrinking grout material to fill any gap between the hardened joint core concrete and the upper part of the precast column; (7) The scaffolding was removed after 2 weeks and the PCBC specimens were ready to test after the CIP-connection had aged a minimum of 28 days. It is noteworthy to mention that in a real application, the precast Ubeam can be placed directly on the corbels of the precast columns at both sides (left and right precast beam), so that the scaffolding could be removed after 7 days.

The joint incorporated two concrete types. One is a plain concrete with a design compressive strength of $30 \mathrm{MPa}$; this was used for the precast concrete beam and column. The other was a SFRC with a design compressive strength of $45 \mathrm{MPa}$, which was used for the CIP-connection. The CIPconcrete has a higher compressive strength than the precast elements because the connection region was expected to be the more vulnerable, and hence experiences greater stresses from the applied loads. Three PCBC specimens were fabricated and all had the same dimension and reinforcement detail. The fiber content in the CIP-concrete was varied, i.e., $0 \%, 0.5 \%$, and $1 \%$ for specimens $\mathrm{P} 2, \mathrm{P} 3$, and $\mathrm{P} 4$, respectively. A $1 \%$ fiber content was the maximum fiber content considered; greater volumes caused practical problems with the placing of the CIPconcrete. The hooked-end steel fiber is used in this study and its properties are presented in Table 1. The mix proportion of CIP-concrete for specimens P2, P3, and P4 is given in Table 2. Four different diameters of steel bar were used for the PCBC specimens, i.e. $8 \mathrm{~mm}$ (for the beam stirrups), $10 \mathrm{~mm}$ (for the longtudinal bars of the U-beam), and $12 \mathrm{~mm}$ and $16 \mathrm{~mm}$ (for the flexural bars of the beam core and the column). The yield strength of the steel reinforcing bars was $500 \mathrm{MPa}$ and the yield strain was 0.0030 .

Table 1. Properties of the steel fibers

\begin{tabular}{l|l}
\hline Brand & Dramix RC 65 35 BN \\
Length $\left(\mathrm{l}_{f}\right)$ & $35 \mathrm{~mm}$ \\
Diameter $\left(\mathrm{d}_{f}\right)$ & $0.55 \mathrm{~mm}$ \\
Aspect ratio $\left(\mathrm{l}_{f} / \mathrm{d}_{f}\right)$ & 65 \\
Tensile strength & $1345 \mathrm{~N} / \mathrm{mm}^{2}$ \\
Young's Modulus $\left(\mathrm{E}_{\text {mod }}\right)$ & $210000 \mathrm{~N} / \mathrm{mm}^{2}$ \\
\hline
\end{tabular}

For these tests, both the column ends were restrained by steel plates which were bolted to the test rig, while the beam end was free. The load was applied vertically to the tip of the beam. No vertical axial load was applied to the top of the column since this tends to enhance the joint shear strength; hence, this load setup represented a worstcase loading scenario [17]. Figure 2A shows the setup of the test.

A quasi-static load was applied to the specimen using displacement control; displacements of $3 \mathrm{~mm}, 8 \mathrm{~mm}, 12 \mathrm{~mm}, 18 \mathrm{~mm}, 24 \mathrm{~mm}, 36 \mathrm{~mm}$, $48 \mathrm{~mm}$, and $60 \mathrm{~mm}$ were used, as shown in Figure 2B. For each displacement two cycles of quasistatic loading were applied. After the second cycle at $60 \mathrm{~mm}$ displacement, the test specimen still appeared to be in good condition. At this stage, there was no significant peak load degradation; all peak loads at all cycles after displacement level of $12 \mathrm{~mm}$ were higher than $75 \%$ of the maximum load in both loading directions. To finish the test, the 
Table 2. Material composition of precast elements and CIP-connection of specimens P2, P3, and P4

\begin{tabular}{lllll}
\hline Materials & $\begin{array}{l}\text { Precast } \\
\text { elements }\end{array}$ & CIP-connection of P2 CIP-connection of P3 CIP-connection of P4 \\
\hline \hline Coarse aggregate $\left(\mathrm{kg} / \mathrm{m}^{3}\right)$ & 1000.55 & 1028.4 & 1028.4 & 1028.4 \\
Fine aggregate $\left(\mathrm{kg} / \mathrm{m}^{3}\right)$ & 818.63 & 685.6 & 685.6 & 685.6 \\
Cement $\left(\mathrm{kg} / \mathrm{m}^{3}\right)$ & 335.82 & 441 & 441 & 441 \\
Water $\left(\mathrm{kg} / \mathrm{m}^{3}\right)$ & 208 & 210 & 213 & 213 \\
Steel fiber $\left(\mathrm{kg} / \mathrm{m}^{3}\right)$ & - & - & 39.25 & 78.5 \\
w/c & 0.62 & 0.47 & 0.52 & 0.52 \\
Slump $(\mathrm{mm})$ & 150 & 140 & 125 & 85 \\
\hline
\end{tabular}
CIP, cast-in-place.
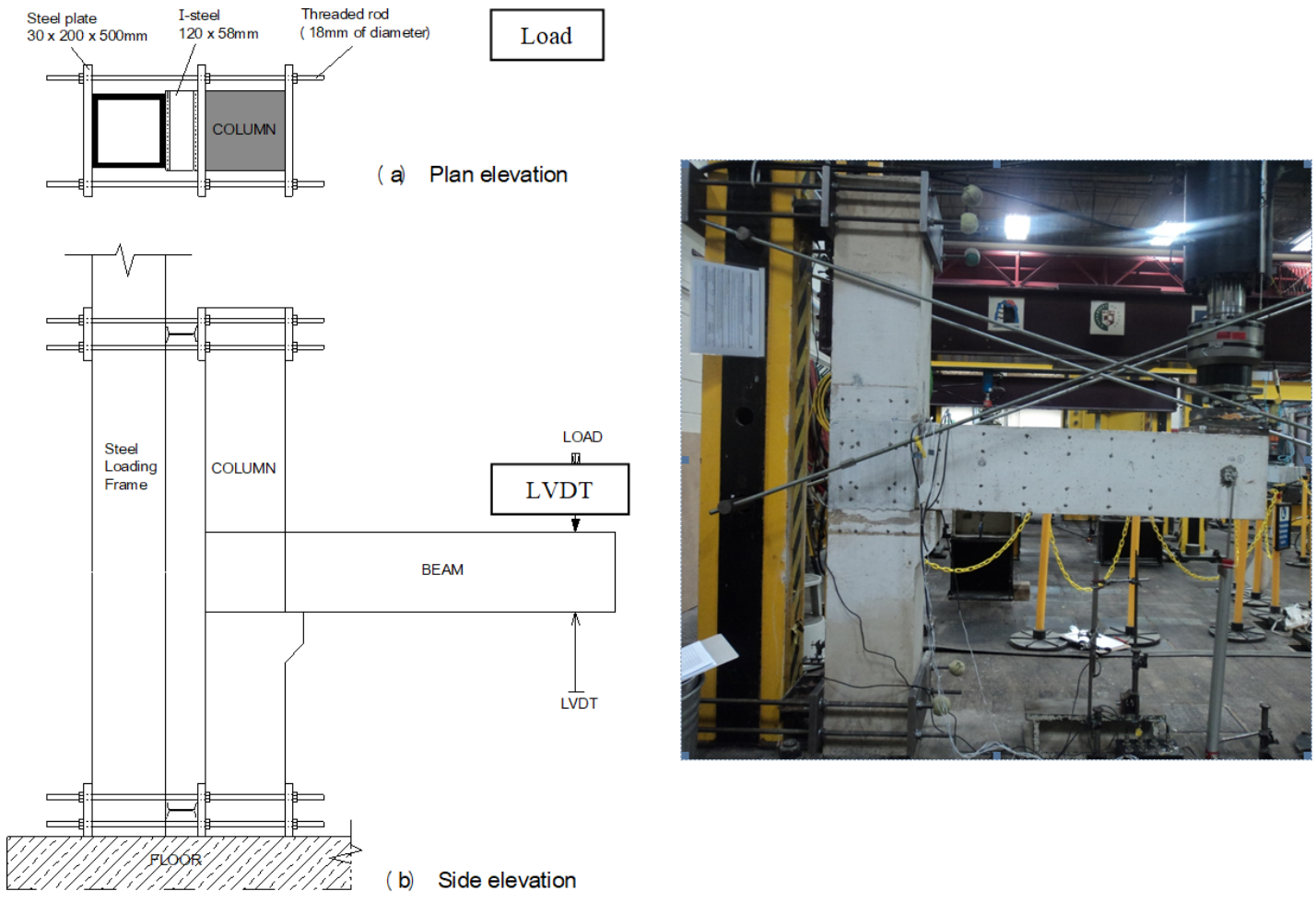

(A)

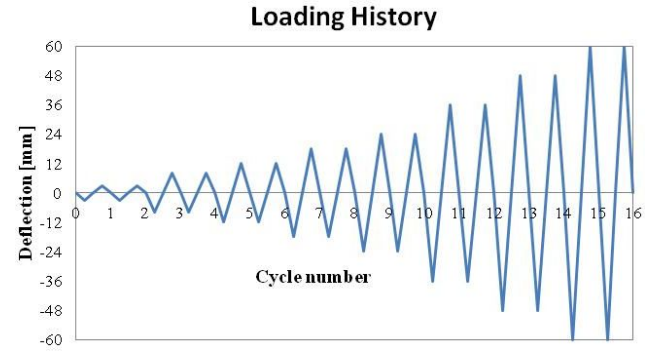

(B)

Fig. 2. (A) Test setup of PCBC specimens; (B) Loading history for reversed cyclic load test. PCBC, precast concrete beam-column. 
Table 3. Average of compressive strength, modulus of elasticity, and modulus of rupture

\begin{tabular}{lllll}
\hline Specimen & $\begin{array}{l}\text { Average compressive } \\
\text { strength }(\mathrm{MPa})\end{array}$ & $\begin{array}{l}\text { Average modulus of } \\
\text { elasticity (MOE) } \\
(\mathrm{GPa})\end{array}$ & $\begin{array}{l}\text { Average modulus of } \\
\text { Rupture (MOE) } \\
(\mathrm{MPa})\end{array}$ \\
\hline \hline P2 & Precast beam & 40.95 & 30.697 & 4.03 \\
& Precast column & 55.87 & 28.940 & 5.42 \\
& CIP-concrete & 50.86 & 31.518 & 5.99 \\
\hline P3 & Precast beam & 36.82 & 30.461 & 5.36 \\
& Precast column & 42.83 & 28.009 & 5.21 \\
& CIP-concrete & 47.36 & 33.782 & 6.06 \\
\hline P4 & Precast beam & 50.58 & 31.304 & 5.88 \\
& Precast column & 51.35 & 29.841 & 5.65 \\
& CIP-concrete & 60.26 & 42.679 & 7.76 \\
\hline
\end{tabular}

Table 4. Comparison of the mechanical properties of the CIP-concrete of the PCBC specimens

\begin{tabular}{llllll}
\hline & $\left(\mathrm{V}_{f}=0 \%\right)$ & $\left(\mathrm{V}_{f}=0.5 \%\right)$ & $\left(\mathrm{V}_{f}=1.0 \%\right)$ & \multicolumn{2}{l}{ Increase compared to $\left(\mathrm{V}_{f}=0 \%\right)$} \\
\hline \hline $\begin{array}{l}\text { Average of compressive } \\
\text { strength (MPa) }\end{array}$ & 50.86 & 47.36 & 60.26 & -6.88 & 18.48 \\
$\begin{array}{l}\text { Average modulus } \\
\text { elasticity (GPa) }\end{array}$ & 31.518 & 33.782 & 42.679 & 7.18 & 35.41 \\
$\begin{array}{l}\text { Average modulus of rup- } \\
\text { ture (MPa) }\end{array}$ & 5.99 & 6.06 & 7.76 & 1.17 & 29.55 \\
\hline
\end{tabular}

CIP, cast-in-place; PCBC, precast concrete beam-column.

load was applied in the negative direction (going down) until failure.

The crack development at every level of displacement was recorded on the test specimen using different colors to indicate the different loading directions.

\section{Results and discussion}

\subsection{Mechanical properties of concrete}

Table 3 provides the average concrete cube strength, modulus of elasticity, and modulus of rupture of the precast units and the CIP-concrete for specimens P2, P3, and P4, each of which was determined on three samples.

Table 4 presents a comparison of the mechanical properties of the CIP-concrete. Adding $0.5 \%$ of steel fiber by volume to the concrete only caused a slight increase in values compared to that of the plain concrete in terms of the compressive strength, modulus of rupture, and modulus of elasticity (i.e., $-6.88 \%, 1.17 \%$, and $7.18 \%$, respectively). However, adding $1.0 \%$ steel fiber by volume of concrete increased the compressive strength, modulus of rupture, and modulus of elasticity significantly (i.e., $18.48 \%, 29.55 \%$, and $35.41 \%$, respectively).

The slight decrease in terms of the compressive strength (i.e., $-6.88 \%$ ) of the CIP-P3 concrete was caused by the amount of water added to the concrete mix. As can be seen in Table 2, the CIP-P3 mix contained more water (i.e., $213 \mathrm{~kg} / \mathrm{m}^{3}$ ) compared with the CIP-P2 mix (i.e., $210 \mathrm{~kg} / \mathrm{m}^{3}$ ). This was done in order to maintain the workability of the fresh concrete due to the inclusion of the steel fibers.

The effect of steel fibers on the compressive strength is not too significant. This is in line 
with the results of Oh [18]; this study found that the compressive strength increase was about $17 \%$ when steel fibers $\left(\mathrm{V}_{f}=2 \%\right)$ were added to the concrete, and less than $10 \%$ at $\mathrm{V}_{f}=1 \%$. In addition, Altun et al. [3] that found that the addition of $30 \mathrm{~kg} / \mathrm{m}^{3}$ of steel fiber decreased the compressive strength of a C30 concrete by approximately $11.5 \%$.

Figure 3 shows the failure mode of the MOR prism concrete. The plain concrete prisms $\left(\mathrm{V}_{f}=\right.$ $0 \%$ ) failed suddenly once the first crack occurred and fractured into two parts. On the other hand, the FRC prism exhibited cracks but did not fully fracture. This is because the random steel fibers bridge the cracks and resist the cracks from developing and widening through the de-bonding and pullingout mechanism and so no sudden fracture occurred.

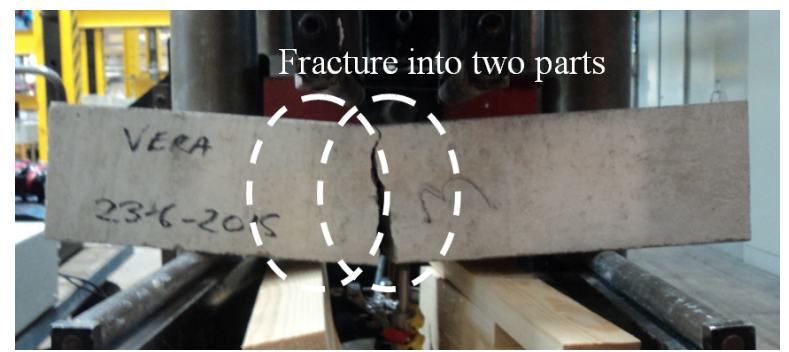

(A)

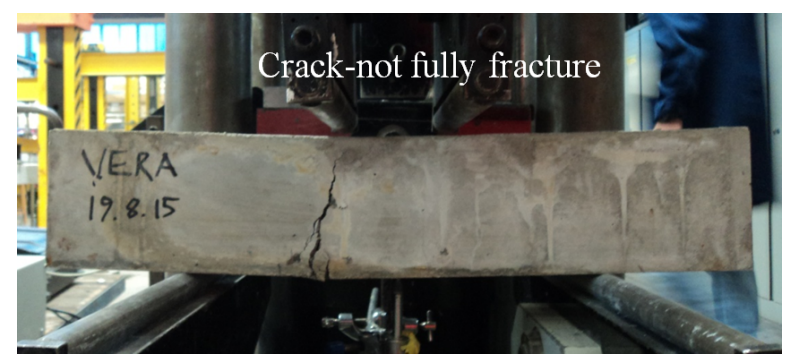

(B)

Fig. 3. Failure mode of the flexural test of the prism, (A) plain concrete, (B) steel fiber reinforced concrete.

The effect of steel fibers in terms of the loaddeflection relationship of the prism tests is presented in Figure 4. It can be seen that the plain concrete $\left(\mathrm{V}_{f}=0 \%\right)$ is a brittle material, with sudden failure as the first crack occurred. This means that the first-crack load is the peak load. A bet- ter performance was observed for the SFRC used in the CIP-connection of the PCBC specimens $\mathrm{P} 3$ and $\mathrm{P} 4$. The curves for the CIP of $\mathrm{P} 4\left(\mathrm{~V}_{f}=1 \%\right)$ showed that after cracking, the load continued to increase. Once the peak load was achieved, the load decreased gradually with the prism exhibiting significant deflection. However, the CIP-connection curve of specimen $\mathrm{P} 3\left(\mathrm{~V}_{f}=0.5 \%\right)$ showed that after cracking, the load decreased gradually accompanied by large deflection. Both SFRC material with $\mathrm{V}_{f}=0.5 \%$ and $1 \%$ showed better ductility in comparison to the plain concrete material.

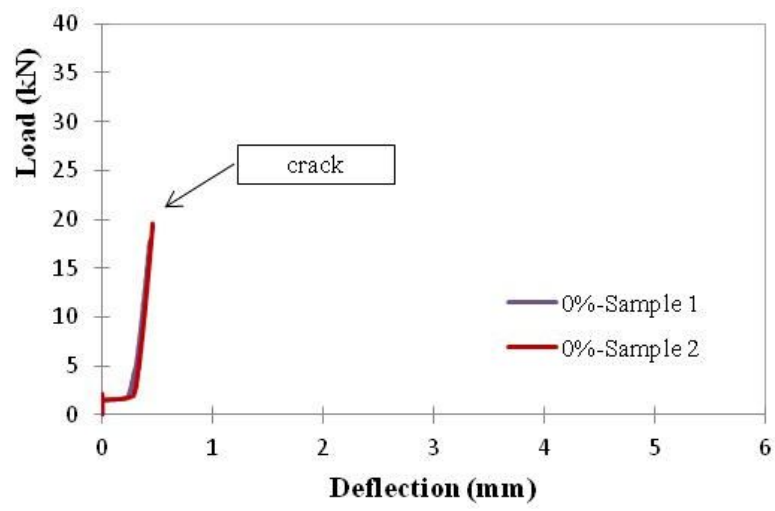

(A)

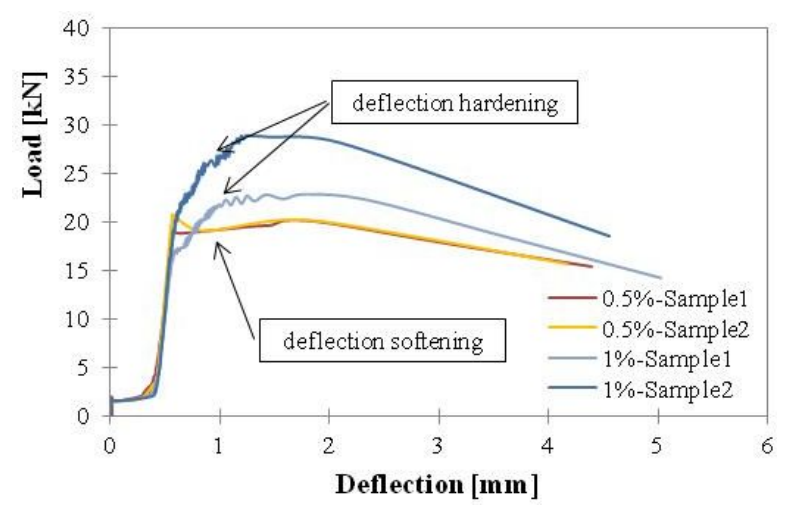

(B)

Fig. 4. Load-deflection comparison for the prisms made of the concrete used in the CIP-connections of (A) Specimen P2 $\left(\mathrm{V}_{f}=0 \%\right)$; (B) Specimen P3 $\left(\mathrm{V}_{f}=0.5 \%\right)$ and $\mathrm{P} 4\left(\mathrm{~V}_{f}=1 \%\right)$. CIP, cast-inplace.

The curves of the SFRC with $\mathrm{V}_{f}=1 \%$ could be categorized as deflection-hardening, as the peak load was higher than the first-crack load. The curves of the SFRC with $\mathrm{V}_{f}=0.5 \%$ could be cat- 
egorized as deflection-softening, due to the firstcrack load and the peak load being similar.

There is a slight difference in the curves for the CIP-concrete containing $1 \%$ steel fibers. This highlights the potential variability when incorporating steel fibers in a mix and the difficulty in obtaining an even distribution of the fibers.

The energy which could be absorbed by the specimen during loading can be calculated as it is equal to the area under the load-deflection curves [19]. It is observed that the area under the load-deflection curves of the SFRC with $\mathrm{V}_{f}=1 \%$ is about $40 \%$ larger than that of the SFRC specimen with $\mathrm{V}_{f}=0.5 \%$.

\subsection{The effect of the steel fiber in the CIP- connection on the behavior of the beam- column connections}

The load-deflection hysteretic loops of the PCBC connections of specimens P2, P3, and P4 are presented in Figure 5. The load was applied at the beam tip, and the deflection was measured at the beam tip. This data is used to investigate the energy dissipation, which is presented in the next section.

It appears that the presence of steel fibers in the CIP-concrete has enhanced the characteristics of the hysteristic load-deflection curves of the PCBC specimens, slightly increasing the maximum load and producing wider loops at each displacement level; this indicates a greater dissipation of energy. The steel fibers within the CIP-concrete also delay crack formation and effect crack propagation. For instance, the diagonal cracks in the joint core on PCBC specimen P2 (with plain concrete as CIPconnection) appeared immediately and occurred at one load level (at the deflection level of $12 \mathrm{~mm}$ ), as can be seen in Figure 6A, whereas the diagonal cracks (diagonal red cracks in specimen $\mathrm{P} 4$, see Figure 6B) were shorter and occurred during several load levels (at the deflection levels of $12 \mathrm{~mm}$, $18 \mathrm{~mm}$, and $36 \mathrm{~mm}$ ) and were spread-out over the surface of the concrete. This behavior is in agreement with the data of the MOR test, which showed that the first crack in the plain concrete $\left(\mathrm{V}_{f}=0 \%\right)$ is followed by a sudden drop in the load-deflection curve (see Figure 4A). However, when the first

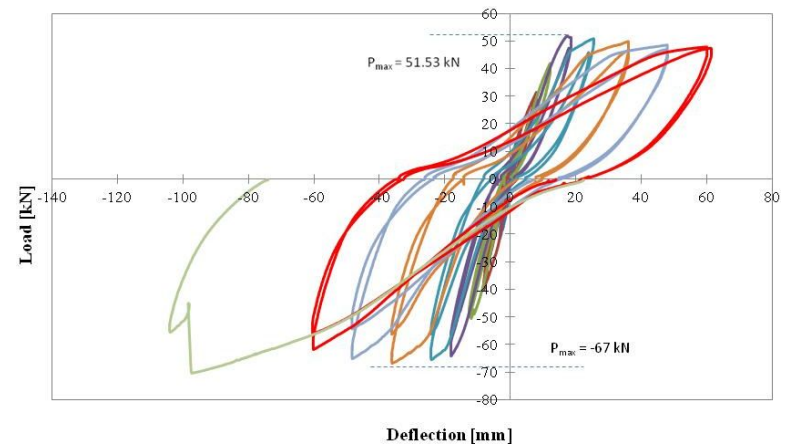

(A)

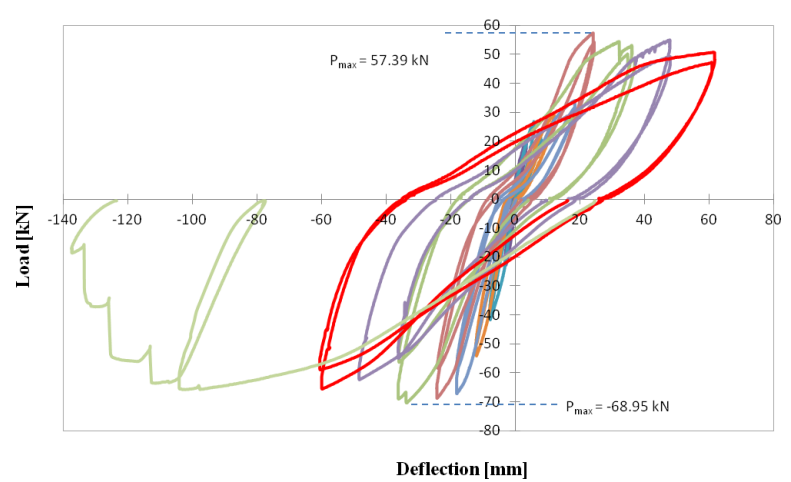

(B)

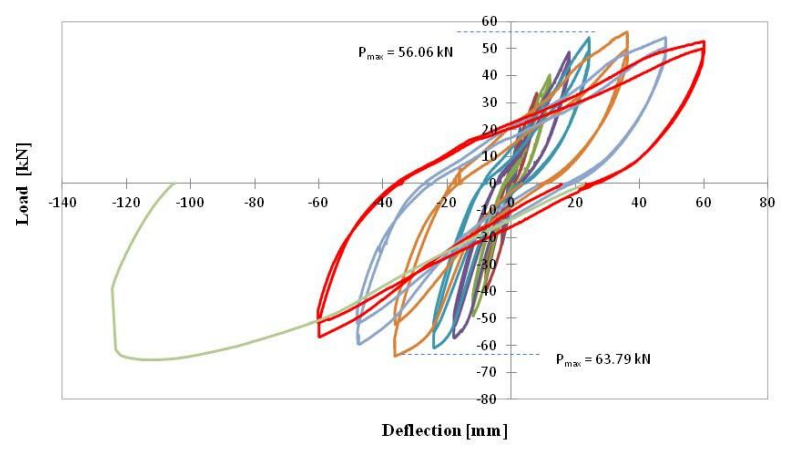

(C)

Fig. 5. Load-deflection hysteresis loops of PCBC specimens: (A) P2 with $\mathrm{V}_{f}=0 \%$, (B) P3 with $\mathrm{V}_{f}$ $=0.5 \%$, (C) $\mathrm{P} 4$ with $\mathrm{V}_{f}=1 \%$. PCBC, precast concrete beam-column.

crack occurred in the SFRC MOR test $\left(\mathrm{V}_{f}=1 \%\right)$, there was subsequent deflection (see Figure 4B). This means that, once cracked, the steel fibers still bridge the cracks and, therefore, restrict the crack propagation (until the steel fibers were pulled-out from the concrete matrix) and delay internal cracks reaching the surface until higher displacements are achieved. 


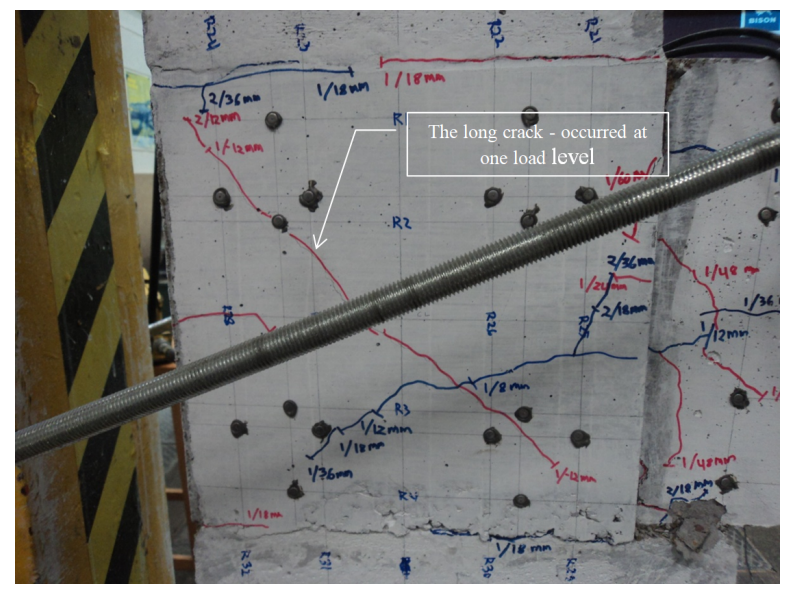

(A)

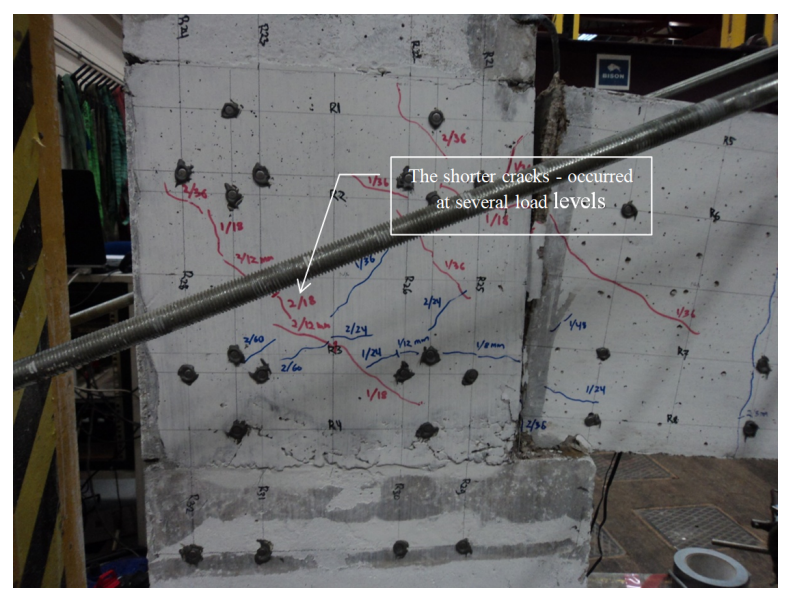

(B)

Notation:
The red marking : The cracks due to the negative loading (downward loading)

The blue marking : The cracks due to the positive loading (upward loading)

18: the tirst tycle of the displacement level of $8 \mathrm{~mm}$.

1/12: the first cycle of the displacement level of 8 mim

$2 / 12$ : the second cycle of the displacement level of $12 \mathrm{~mm}$

And so on

Fig. 6. Crack pattern in the joint core (CIP-concrete): (A) $\mathrm{P} 2$ with $\mathrm{V}_{f}=0 \%$, (B) $\mathrm{P} 4$ with $\mathrm{V}_{f}=1 \%$. CIP, cast-in-place.

The energy dissipation of a structure indicates the ability of a structure to resist the loading from an earthquake through inelastic deformation. Greater energy dissipation will improve the seismic performance of a structure. Energy dissipation was calculated as the area enclosed by the hysteretic loops in the corresponding beam tip load vs. deflection graphs $[12,20]$. Cumulative energy dissipation (CED) during the reverse cyclic load test was calculated by summing the energy dissipated in consecutive load-displacement loops throughout the test, as presented in Figure 7. In order to eliminate the effects of the concrete strength variation in the different beam-column specimens, the calculated energy dissipations were normalized with respect to the area of elastic-perfectly plastic rectangular stress block at each cycle using Eq. (1) $[12,21]$. Figures 8 and 9 present the CED and the normalized energy dissipation (NED) of PCBC specimens $\mathrm{P} 2, \mathrm{P} 3$, and $\mathrm{P} 4$, respectively.

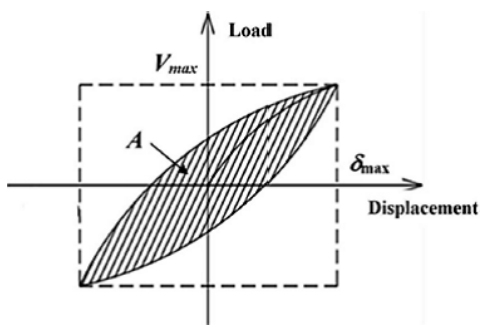

Fig. 7. Definition of normalized dissipated energy normalizing hysteretic energy dissipation at each load cycle [12].

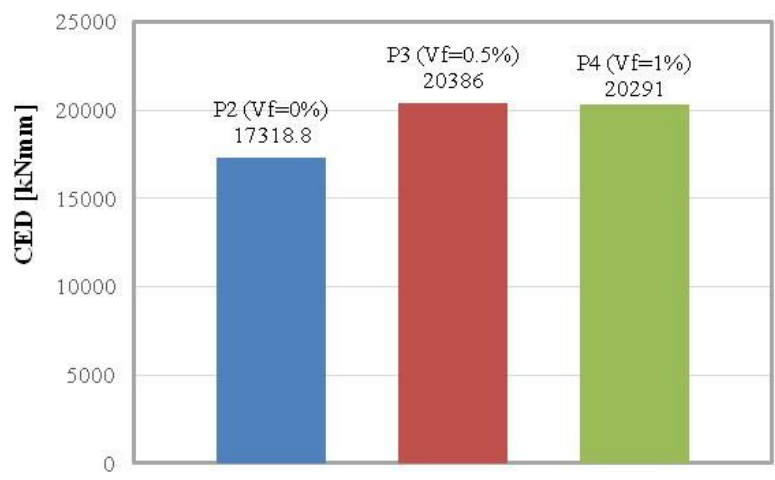

Fig. 8. CED of PCBC specimens. CED, cumulative energy dissipation; PCBC, precast concrete beamcolumn.

From Figure 8, it is clear that the PCBC specimens with steel fibers had a higher CED than the PCBC specimen without fibers, i.e., about $17.7 \%$. From Figure 9, we observe that specimen P4 has the highest result of NED, particularly at the beginning of the test, where more cracks were developed at this stage. The presence of steel fibers in the CIPconcrete appears to improve the energy dissipation capacity of the PCBC joint. 


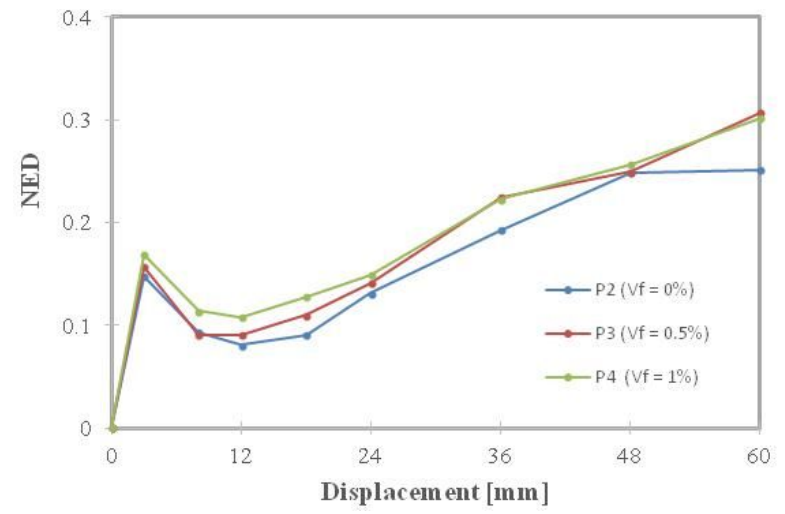

Fig. 9. NED of PCBC specimens P2, P3, and P4. PCBC, precast concrete beam-column; NED, normalized energy dissipation.

Theoretically, specimen P4 should have performed better than specimens P2 and P3 due to the greater fiber content. In trying to unearth an explanation for the energy dissipation results, an examination of the experimental procedure during the construction of the specimens was performed. It was discovered that tape had been stuck to the polystyrene void formerly used to manufacture the precast $\mathrm{U}$-beam for $\mathrm{P} 4$; this had inadvertently caused a smooth surface to the inner walls of the U-beam, lowering the bond at the interface between the U-beam and the beam CIP-concrete. The lower energy dissipated by $\mathrm{P} 4$ can be explained by the lack of bond/reduced composite behavior between the two components; the effect of this can also be seen in Figure 8 where the curve decreases (the curve for specimen P3 increases).

$$
\begin{aligned}
& \text { Normalized Energy Dissipation (NED) } \\
& =\frac{A}{4 V_{\max } \delta_{\max }}
\end{aligned}
$$

where $V_{\max }$ is the average of the maximum load; $\delta_{\text {max }}$ is the average of displacement for positive and negative loading directions; and $A$ is the area enclosed by the hysteretic loops.

Stiffness degradation, in this study, was measured using the secant stiffness $\left(\mathrm{K}_{s e c}\right)$ principle (peak-to-peak stiffness); this was calculated at every displacement level $(3 \mathrm{~mm}, 8 \mathrm{~mm}, 12 \mathrm{~mm}$, $18 \mathrm{~mm}, 24 \mathrm{~mm}, 36 \mathrm{~mm}, 48 \mathrm{~mm}$, and $60 \mathrm{~mm})$. Secant stiffness is defined as the slope of the straight line between the maximum load of the positive and negative direction, at the last cycle of each displacement level or drift ratio level $[14,20]$. The stiffness-deflection relationship is presented in Figure 10 , and used to compare the stiffness degradation of the beam-column specimens from one cycle to the following cycle.

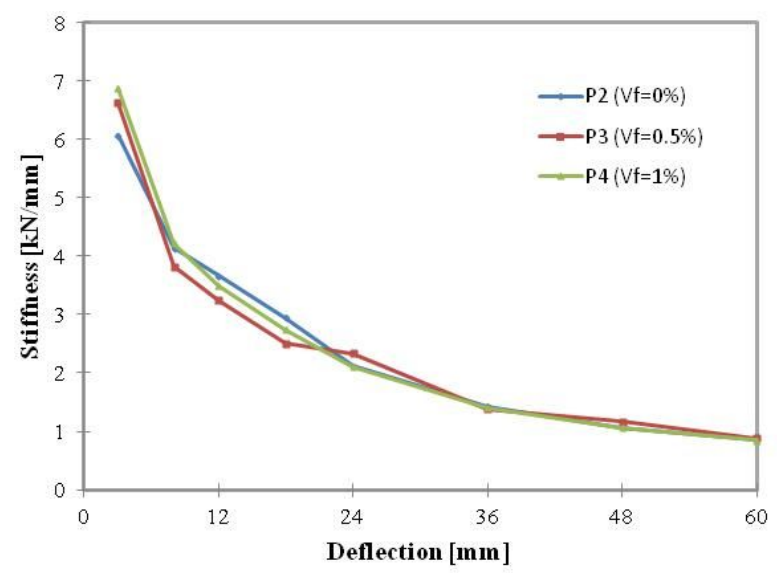

Fig. 10. Secant stiffness degradation of the PCBC specimens. PCBC, precast concrete beam-column.

Figure 10 shows that for all specimens, as the deflection increases, the stiffness decreases. At the beginning of the test (the deflection level of $3 \mathrm{~mm}$ ), P4 had the highest secant stiffness.

A high energy dissipation does not mean a high secant stiffness. Energy dissipation is obtained from the area enclosed by the load-displacement loop. Steel fibers within the CIP-concrete cause wider loops, meaning it has higher energy dissipation. On the other hand, the secant stiffness is the slope of the straight line between the maximum load of the positive and negative direction. At displacement level of $36 \mathrm{~mm}, 48 \mathrm{~mm}$, and $60 \mathrm{~mm}$ the maximum load in both directions for all PCBC specimens are about same, hence the similar secant stiffness.

The effect of steel fiber on the stiffness degradation was only apparent at the beginning of the test (from deflection level of $3 \mathrm{~mm}$ to $24 \mathrm{~mm}$ ). This finding is also in agreement with Ganesan et al. [5] and Marthong and Marthong [8]. From the deflection level of $36 \mathrm{~mm}$ to $60 \mathrm{~mm}$, the curves appear similar. However, the connections with steel fibers 
in them absorb more energy (the loops were fatter in comparison with the connection without steel fiber) and more energy absorption is also indicated by the extended flatter part of the curve representing the plastic behavior.

The steel fibers that are spread evenly within the concrete will increase the stiffness of the uncracked concrete matrix, which also therefore increases the joint stiffness. The greater the quantity of steel fibers, the larger the increase in joint stiffness. However, this only appeared to apply at the beginning of loading. After the concrete has cracked it appears that the influence of steel fibers on the joint stiffness decreases.

\section{Conclusions}

Based on the test results, the mechanical properties of SFRC tests and its application on the connection of precast beam-column under the reversed cyclic test, the following conclusions are drawn:

1. The addition of $0.5 \%$ and $1 \%$ of steel fibers by volume appear to change the properties of concrete from a brittle material to a more ductile material. The concrete with steel fiber $\mathrm{V}_{f}=0.5 \%$ has deflection-softening characteristic, whereas the concrete with steel fiber $\mathrm{V}_{f}=1 \%$ has deflection-hardening characteristics (as shown in MOR test). This means that once the applied tensile stress exceeds the tensile strength capacity of the concrete and the first crack occurs, the stress in the beam element can still increase. During this hardening stage, the steel fibers, when spread uniformly within the concrete matrix, prohibit the crack extension until they are pulled out of the concrete matrix.

2. The use of SFRC, for the material connection of a typical exterior precast concrete beam-to-column joint in this study, can alter the pinch load-deflection hysteretic loops, making them wider, which means an increase in the energy dissipation (about 17\%) and the ductility of the joint in comparison with the PCBC joint using plain concrete as the material connection (CIP-concrete). The addition of fibers in concrete is not to improve strength (even though there is a little improvement), but primarily to control cracking (through friction forces between steel fiber and the concrete), and improve the toughness or energy absorption capacity. It is clear from the tests that the steel fibers delayed the onset of cracking and slowed down the crack propagation, resulting in shorter cracks in the joint core and the top surface of the beam core (as shown in specimen $\mathrm{P} 4: \mathrm{V}_{f}=1 \%$ ). This behavior correlates well with the deflection-hardening characteristic found from the MOR test.

3. The steel fibers will also increase the joint stiffness until the first crack occurred. After the concrete has cracked, the influence of steel fibers on the joint stiffness decreases.

4. In general, the application of the Dramix RC $6535 \mathrm{BN}$ steel fiber to the concrete used in the CIP-connection of a typical PCBC joint developed by Noorhidana \& Forth [12], can improve the performance of the joints against cyclic loads.

\section{Acknowledgements}

This research was sponsored by the Ministry of Research Technology and Higher Education, Republic of Indonesia, and the School of Civil Engineering, University of Leeds.

\section{Conflict of interest}

V. A. Noorhidana and J. P. Forth state that there are no conflicts of interest.

\section{Ethical approval}

This article does not contain any studies with human participants or animals performed by any of the authors.

\section{References}

[1] Ezeldin AS, Balaguru PN. Normal and high strength fiber-reinforced concrete under compression. J Mater Civil Eng. 1992; https://doi.org/10.1061/ (ASCE) 0899-1561 (1992) 4:4 (415).

[2] Lee MK, Barr BIG. An overview of the fatigue behavior of plain and fiber reinforced concrete. Cem Concr Compos. 2004; https://doi.org/10.1016/ S0958-9465 (02) 00139-7.

[3] Altun F, Haktanir T, Ari K. Effects of steel fiber addition on mechanical properties of concrete and $\mathrm{RC}$ 
beams. Constr Build Mater. 2007; https: //doi.org/ 10.1016/j . conbuildmat .2005.12.006.

[4] Chao SH, Naaman AE, Montesinos GJP. Bond behavior of reinforcing bars in tensile strain-hardening fiber reinforced cement composites. ACI Struct J. 2009;106(6):897-906.

[5] Ganesan N, Indira PV, Sabeena MV. Behavior of hybrid fiber reinforced concrete beam-column joints under reverse cyclic loads. Mater Des. 2014; https://doi. org/10.1016/j.matdes. 2013.08.076.

[6] ACI 544.1R-96. State-of-the-art report on fiber reinforced concrete. American Concrete Institute-ACI Committee; 1996.

[7] Soroushian P, Bayasi Z. Fiber type effects on the performance of steel fiber reinforced concrete. Mater J. 1991; https://doi .org/10.14359/1883.

[8] Marthong C, Marthong S. An experimental study on the effect of PET fibers on the behavior of exterior $\mathrm{RC}$ beam-column connection subjected to reversed cyclic loading. Structures. 2016; https://doi.org/ 10.1016/j.istruc.2015.11.003.

[9] Ganesan N, Indira PV, Ruby A. Steel fiber reinforced high performance concrete beam-column joints subjected to cyclic loading. ISET J Earthq Technol. 2007;44(3-4):445-56.

[10] Maya F, Zanuy C, Albajar L, Lopez C, Portabella J. Experimental assessment of connections for precast concrete frames using ultra high performance fibre reinforced concrete. Constr Build Mater. 2013; https : // doi.org/10.1016/j. conbuildmat. 2013.07.002.

[11] Bull DK, Park R. Seismic resistance frames incorparating precast prestressed concrete beam shells. PCI J. 1986; https://doi.org/10.15554/pcij. 07011986.54.93.

[12] Parastesh H, Hajirasouliha I, Ramezani R. A new ductile moment-resisting connection for precast concrete frames in seismic regions: an experimental investigation. Eng Struct. 2014; https://doi.org/10.1016/ j.engstruct. 2014.04.001.
[13] Bhatt P, Kirk DW. Test on an improved beam column connection for precast concrete. ACI J. 1985;82(6):834843.

[14] Ertas O, Ozden S, Ozturan T. Ductile connections in precast concrete moment resisting frames. PCI J. 2006; https://doi.org/10.15554/pcij. 05012006.66 .76 .

[15] Li B, Yip WK, Leong CL. Hybrid-steel concrete connections under reversed cyclic loadings. In: Pasific Conference on Earthquake Engineering; 2003.

[16] Noorhidana VA, Forth JP. Precast concrete beam-tocolumn connection using interlocking bars, An alternative. Concr Plant Int. 2016;6:200-4.

[17] Park R. Simulated seismic load tests on reinforced concrete elements and structures. In: Earthquake Engineering, 10th World Conference, Rotterdam; 1994.

[18] Oh BH. Flexural analysis of reinforced concrete beams containing steel fibers. J Struct Eng. 1992; https://doi.org/10.1061/(ASCE) 0733-9445 (1992) 118:10 (2821).

[19] Shannag MJ, Ziyyad TB. Flexural response of ferrocement with fibrous cementitious matrices. Constr Build Mater. 2007; https://doi.org/10.1016/j. conbuildmat .2006.06.021.

[20] Said AM, Nehdi ML. Behavior of beam-column joints cast using self-consolidating concrete under reversed cyclic loading. In: 13th World Conference on Earthquake Engineering, Canada; 2004.

[21] Hidalgo PA, Jordan RM. Strength and energy dissipation characteristics of reinforced concrete walls under shear failure. In: Proceedings of the 11th World Conference on Earthquake Engineering, Acapulco; 1996.

Received 2021-04-07 Accepted 2021-09-13 